\title{
PERSONAL AND SPIRITUAL DEVELOPMENT IN CONTEMPORARY ROMANIA: IN SEARCH OF AMBIVALENCE
}

\begin{abstract}
ANCA SIMIONCA ${ }^{1}$
ABSTRACT. This paper is an inquiry into the blooming sector of personal and spiritual development in contemporary Romania. It is based on interviews with providers of such services, on content analysis of blogs and books dedicated to the topic, and on participation in several workshops. The critical literature linking the proliferation of the field of personal and spiritual development with the increasing pervasiveness of neoliberal logic has highlighted some of the features of the subjectivity invoked in these programmes: the sovereignty of the self in relation to its environment, the lack of importance of social ties and solidarity, and the lack of importance of the community. This analysis explores the empirical material in searching for the main points of ambivalence in relation to these desiderates, as well as the mutations that can be identified in the privileged sites of production of individuality that are personal and spiritual development workshops and trainings. ${ }^{2}$
\end{abstract}

Keywords: personal development, spiritual development, neoliberal subjectivity

The most superficial glance at the shelves in any contemporary bookstore in Romania cannot fail to notice the predominance of titles pertaining to selfhelp, personal and professional development, and alternative spiritualties. At the same time, interviews with employees about their working life experiences and careers (Petrovici, 2015; Simionca, 2015) are brimming with references to people's commitment to personal development, their desires in this direction and the concrete actions they undertake. While most visible in the accounts of the young and educated, the same imageries of a constant need to "develop" oneself are structuring the accounts of both skilled and unskilled workers (Petrovici, 2015). Interviews and public declarations of employers also abound in references to the importance of the soft skills of employees, among which the desire to

\footnotetext{
${ }^{1}$ Sociology Department, Babeș-Bolyai University Cluj-Napoca, e-mail: anca.simionca@gmail.com.

2 This work was supported by a grant of the Romanian National Authority for Scientific Research and Innovation, CNCS - UEFISCDI, project number PN-II-RU-TE-2014-4-2515.
} 
learn new things and to grow as a person are central. Social media is flooded by reposts of blog entries describing various techniques to reach one's goals, and motivational entries explaining the need to achieve a state of mind that directs the self towards constant evolution and mindfulness. Equally present are advertisements that invite people to experience first-hand the benefits of various techniques and strategies: Neuro-linguistic Programming (NLP), Theta Healing, holotropic breathing, familial constellations, coaching sessions, professional development, or personal trademark techniques of various providers.

This phenomenon has not failed to capture the attention of critical literature. On the contrary, it has received increasing attention both from religious studies scholars, interested in the transformations of the religious and spiritual fields and their relation to the economic sphere, and from a variety of critical social scientists questioning 'the new spirit of capitalism'. The commonality of all the programs of personal development despite their variety is the centrality held by the individual self, its resourcefulness, and the type of object of crafting that it becomes. Scholars question the consequences the scripts for subjectivity embedded in the personal and spiritual development programmes have on contemporary possibilities for solidarity, commonality, and policy.

For this paper, I rely on twenty interviews conducted with providers of services of personal and spiritual development, participant observation in three workshops (two of them between two and three hours long, and one that lasted for seven days, nine hours a day), between July and November 2016. They were complemented with content analysis of 20 blogs and several personal development books. Given the logic of the overall research project this material is part of, all the above were selected under the condition that they would have at least a minimum opening towards spiritual development, not simply personal development. Therefore, I interviewed psychologists whose services included spiritual development, yoga trainers, coaches, NLP practitioners, spiritual and professional development providers.

One of the first findings of our study was the diversity of the practices that are subsumed under these generous labels and the fact that despite this diversity, they do constitute a field: actors are aware of and constantly try to position themselves in relation to the others, either in opposition, or in direct continuity. Critical voices, both in the blogosphere and in actual workshops or interviews are easily visible, despite a more general agreement that "diversity is good, there is place for all these different ways of trying to do these things" ${ }^{\text {. }}$

\footnotetext{
3 This exact formulation or close variations of it were used by a majority of my interviewees, and is recurring in the blog posts discussing the field of personal and spiritual development itself.
} 
There are ongoing debates about what is and what is not personal development, what is the role of the scientificity of the claims made by providers or authors, what is the optimal relationship with the Orthodox Church, with mainstream psychology, with oriental religions and practices, with medicine. Even within the same niche of practice, like NLP, there are several varieties of relating to the theory, and each trainer attempts to personalize their approach, so as to situate themselves in relation to the alternative providers. The professionalization of these services is a great stake for all the actors involved (Bondi, 2005; George, 2013; Makinen, 2014). All the providers that I interviewed incorporate in their visions and techniques explicit elements of spirituality. However, none of those I studied have as main speciality highly spiritual practices such as Theta Healing, Reiki, shamanism, or familial constellations.

The analysis in this paper follows the logic of trying to identify outlier cases in relation to the theoretical expectations set by the literature. It is therefore not an attempt to offer a description of the whole field, and it is from the onset an account of a minority of situations. All the examples I offer are from workshops I participated in, as it is in these instances that involve interactions and challenges on the part of participants rather than in the neat descriptions in blog entries that ambivalences can be documented.

It is beyond doubt that the empirical material analysed offers abundant support for the concerns raised by the authors in the literature review. However, as this paper is one of the first attempts to analyse the wide diversity of material, I start from those elements observed that do not neatly fit into the descriptions highlighting the perfect overlap of the neoliberal scripts for subjectivities and the practices of personal and spiritual development. Therefore, this article explores the empirical material in searching for the main points of tension and ambiguity, as well as the possible mutations that can be identified in the privileged sites of production of individuality that are the personal and spiritual development workshops and trainings.

First, I briefly discuss the centrality of initiative employability in today's understanding of the sources of equilibrium in the relationship between the labour market and individuals and highlight the main points of critique against this hegemonic understanding. Second, I refer to some of the recent literature looking at a variety of practices of personal development by questioning its relationship to the neoliberal economic vision. Finally, I take three of the main conclusions of the critical literature I engaged with and discuss them in relation to my empirical material: the sovereignty of the self, the irrelevance of social ties and the lack of importance of the community within these practices. 


\section{Employability, neoliberal subjectivities, and personal development}

Achieving good rates and quality of employment is one of the central topics of political, policy, and social debates of our times. One of the most visible trends in the main parameters of discussions surrounding the appropriate and feasible ways in which to achieve the desiderates of prosperity for both individuals and businesses is the shift away from the structural aspects of the demand side towards the supply side of the labour market. Employability is a concept with a long history and different nuances (Chertkovskaya, 2013; Chertkovskaya et al., 2013; Fejes, 2010; McQuaid et al., 2005). After the 1980s, however, it is its least complex and most one-sided version that became dominant in the public and policy discourse: the 'initiative employability', a vision of the relationship between individuals and the labour market that makes the former the main target of employment policy. This involves trying to influence the economy in such a way as to provide plentiful and good employment for the population; the mismatch between the supply and demand of labour is thought to be solved by making the individuals more dynamic and capable of adjusting their life trajectories, skills, and understandings of their role to the changes of the economic environment. The gist of the argument is that individuals should think of themselves as an ever-expanding bundle of skills and abilities, always amenable to refashion their professional identity, willing to change geographical locations and to show the capacity to adapt to new situations. The key to security is 'flexicurity', namely the way for individuals to make sure they have security in their lives lays in their capacity to adapt to whatever the structural conditions bring about (Wilthagen and Tros, 2004). The lack of such capacity is deemed as the failure of individuals, and leads to their lack of employability (Chertkovskaya et al., 2013; Ten Bos and Rhodes, 2003).

There has been a consistent wave of criticism towards the hegemony of initiative employability as the main lens for understanding the employment relations and venue for policy. The first line of argument focuses on the technical difficulties of operationalizing or measuring in a reliable way the concept of employability and therefore the incapacity to gather empirical evidence to support or refute the hypothesis. Chertkovskaya and her colleagues argue that employability on the ground is rather synonymous with 'communication', 'adaptability', 'enthusiasm', 'openness to others', 'creativity', or 'autonomy' (Chertkovskaya, 2013; Chertkovskaya et al., 2013). However, it is very difficult to assess the extent to which in any given situations it was indeed the presence or absence of these 'soft skills' that made the difference between success or failure in getting a good job, or in having high levels of performance in it. Permeating much of the current education system as well, the emphasis of soft skills 
coupled with the capacity to learn new skills on the job is the taken for granted truth. Yet, it is not really possible to test the reality of these assumptions, thus making the paradigm of initiative employability visibly a mere ideological construct (Fejes, 2010).

The second problematic aspect with the initiative employability paradigm is the way in which it casts the responsibility: employers and governments have the role of facilitating the encounter between the demand and the supply of labour, but the ultimate responsibility is of the individual, their capacity to foresee and grab opportunities, to adapt and to change in order to accommodate the ('natural') instability of the economy. Thirdly and most relevant for the current discussion, the structural barriers that individuals are facing, the inequality of opportunities and the sources of privilege and oppression are swiped under the rug of personal will and willingness to have a good life (Chertkovskaya et al., 2013).

Scholars such as Nicholas Rose have made convincing arguments about the emergence of a particular type of subjectivity within the hegemonic neoliberal governmentality, which refers to

the ways in which subjects are governed as market agents, encouraged to cultivate themselves as autonomous, self-interested individuals, and to view their resources and aptitudes as human capital for investment and return. Neoliberal governmentality presumes a more or less continuous series that runs from those macro-technologies by which states govern populations, to the micro-technologies by which individuals govern themselves, allowing power to govern individuals "at a distance," as individuals translate and incorporate the rationalities of political rule into their own methods for conducting themselves (Binkley, 2009:62).

The booming sector of personal development discourses and related practices has led researchers' interest towards making use of this theoretical framework in order to illuminate the particular ways in which individuals become embedded in a life-view that is centred on their own agency as the single most important factor of success. An abundance of books, audio and video material, blogs, courses, workshops, trainings, and retreats invite people to reconceptualise their lives in a manner congruent with these principles. This sector offers a good insight into the 'micro-technologies' of self-government and the way they are produced on the ground. Katariina Makinen's discussion of working life coaches as crucial actors in the process of the individualization of the relation between capital and labour is very convincing. Her account echoes the criticism brought to the paradigm of initiative employability, and shows in an empirically dense manner the way in which social contradictions are translated in the process of coaching into individual contradictions. 
As long as one has to work for a living (the proletarian condition), even the best resources will not save one from being penetrated by the antagonism of how to be certain of one's worth as an individual if the worth of the individual is measured in terms of the increasingly precarious labour market. This I suggest is the class antagonism that structures the individual lives of those involved in coaching. [...] In other words, coaching encourages one to internalize the labour-capital relation and its inherent contradictions, and once this relation has been internalized, then self-reflexivity and self-development are offered as a solution to the insecurities that follow (Makinen 2014: 838).

A consistent and growing body of literature started documenting empirically the terms in which the neoliberal subjectivities are constructed (Binkley, 2011; Bondi, 2005; Makinen, 2014; Pagis, 2016; Türken et al., 2015; Trifan, 2015). An eloquent example is the study of Türken and colleagues, who have analysed two newspapers, one in Norway and one in Turkey, in order to describe the way the "interrelated discourses of rationality, autonomy and responsibility, entrepreneurship, and positivity and self-confidence [...] constitute the neoliberal subject in ways consonant with neoliberal governmentality" (Türken et al. 2015:1).

Within this larger interest area, there are a few voices that argue for a more careful analysis of the phenomena. Having a similar starting point, that of analysing the practices of counselling in relation to the neoliberal logic, Liz Bondi reaches only a partially overlapping conclusion with the above-mentioned studies (Bondi, 2005). Her position in the debate internal to the field of psychology and psychoanalysis referring to whether psychotherapies are inherently individualising and de-politicising or actually have subversive openings is "to argue for a more ambivalent reframing that is neither condemnatory nor celebratory of the politics of counselling" (Bondi 2005:497). She further explores the ambivalences and the straightforward oppositions to the neoliberal scripts that the practices of counselling she studied entail.

The study of Türken et al. I referred to above ends with a rather similar call for further investigation, despite their own study's conclusions, which did not leave much space for ambivalence. They argue, following Morgen and Gonzales (2008), for the need to pay special attention to the existence of counterhegemonic moves within the neoliberal discourse and practice. Jaramillo and Carreon (2014) ask the uncanny but crucial questions regarding the relationship between activism and political movements, and some of the values that are central in the neoliberal subjectivity script as well. In their discussion of revolutionary and decolonial praxis of social movements, they look into "the relationship between neoliberal capitalism and subjectivity as it pertains to the emergence of new social actors in revolutionary movements and its influence 
on the emergence of a pedagogy of 'buen vivir' (Jaramillo and Carreon 2014: 394). Dassinger (2013) discusses in a very provocative manner the situation of unions trying to put forth pedagogies of resistance for the unemployed in the context of the strong neoliberal subjectivation processes inscribed in the programs of re-professionalizing directed at them.

While it is beyond the scope of this exploratory paper to engage with the ramifications of the questions raised, I find the insights of the last cluster of authors crucial in guiding the relevance of analysing the empirical instances in which processes of subjectivation undoubtedly occur. Researching the phenomenon of personal development is at the same time a matter of documenting the resonances or direct instances of neoliberal logic, as well as a matter of making visible the ambivalent ways in which both providers and consumers/clients of services of self and spiritual development relate to the normative milieu in which they operate. In the following sections, I will refer to three of the main expectations of critical literature in relation to the continuity between the neoliberal personhood script and the services of personal and spiritual development and I will highlight the ambivalence that actually characterizes the empirical sites of subject production.

\section{The sovereign individual and her relationship with the environment}

The central preoccupation of the critical literature could be summed up in the concern with the way the relationship between the individual and the wider structures in which she is embedded is conceptualized: the individual is invited to think of herself as possibly independent of her environment, as having the capacity to shape her life and conditions around her solely as a result of her will and actions.

This means that the practices of coaching rely on the figure of the sovereign individual in a manner which makes all questions of the structural limits of the individual and social bonds fade into the background as if they did not exist at all, even though they do (Makinen 2014: 829).

True as these statements might hold when reading self-help materials, the processes at the empirical sites of production of such individuality are, however, more ambiguous than that.

I will take NLP as one such example of an ambiguous relationship to the idea of the independent individual. On the one hand, even the briefest analysis of the promises that a workshop of NLP makes highlights the centrality of the individual self as the main agent in one's life, describing transformations of 
the self and of the attitudes of the self towards the world as directly translating into improved quality of life. None of the blog entries or ads for workshops that I came across mentioned explicitly the power of structural forces over individual lives as a way of tempering statements of the ultimate power of the individual to shape their livelihoods. On the other hand, the actual experience of such a workshop cannot be described in a satisfactory manner as an occasion in which the structural limits are ignored and unbounded individual autonomy declared.

The first idea that the trainer presented in the introductory lecture of the NLP course I took part in was "the map is not the territory". The 'map' quickly became one of the main tools used by the trainer and a shortcut to reminding the participants about the situatedness of their experiences. A great deal of effort was put in making sure that each participant realizes that there is a sharp distinction between the representations of any reality that we operate with internally and the reality itself. Consistent with sociological wisdom, the idea of "the map is not the territory" places from the onset the individual in the centre of preoccupations, not only as the source of all solutions and resources, but also as the source of all distortions. We were explained that there is no such thing as objective knowledge, or a complete, correct, or objective description of any reality, that the mental constructs we operate with are the result of the filtering done by each of us through our senses, and therefore will never equal reality itself. One of the consequences of this ontology is indeed that people are invited to think that it is not necessarily realty itself that is problematic in any given situation, but their representation of it and that, therefore, the solution is to change the representation, the 'map'.

There was, however, another consequence that became apparent in the way the workshop was conducted, namely the fact that due to the limitations of our own representations ('the map'), we must have very limited confidence in our understanding of the others and what their life situations are, and must question that understanding. This principle was actually used by the trainer not so much to foster an image of the sovereignty of representations over reality, but to temper the participants' sense of understanding everything about the other's problems and their quickness in offering solutions. The 'filters' that mediate between reality and our mental constructs are not simply described as 'individual differences', but as systematic ones, stemming from the structurally different positions we have, that actually shape the very experiencing of reality: gender, age, level of education, geographic position, wealth, family, networks, values, profession etc. Consequently, the work of 'personal development' starts with and keeps enclosing what the trainer called "the purification of our filters", namely becoming aware of the fragility 
of our mental constructs and the small likelihood of being capable to grasp the hardship and problems another person goes through, followed by a constant effort to transcend these limitations.

For example, in one of the practical exercises, Ioana 4 , a 40 years old woman, with a rural background, having now graduated from university and working in a firm, was discussing her desire to be more assertive with her boss. Mircea, a 32 years old man, holding a middle management position in a firm, coming from an intellectual background was reminded of his own 'status filter' when voicing an unsolicited piece of advice on how easy it would actually be for Ioana to "just be more self-confident" in relation to her boss. Mircea was told by the instructor that he viewed the situation through his own filter of an educated person coming from a privileged background, who consequently does not have a representation of the difficulties a person not having this background faces in that situation. Ioana was later indeed encouraged by the trainer to change her perception of the situation and mobilize internal resources, but not by denying the inherent structural barriers that were there due to (what I now here call) her lower class background or gender. Our male colleague's intervention was sanctioned exactly because it assumed the sovereignty of the individual, failing to be sensitive to the non-individual factors that were structuring the situation.

\section{The role of social ties}

Another dimension of the centrality of the individual inscribed in most of the personal development scripts refers to the encouragement the person is given to make herself the centre of her preoccupations, thus inviting a world in which social ties and solidarity are not valued (see for example Makinen, 2014). However, it is not necessarily the case that the transformations called for by the programs of self-development take clients in the direction of a lack of interest, care, or nurturing for others. While the idea of personal responsibility and boundaries is clearly instilled, it is often times turned around towards describing the responsibility of the others, an exercise in which the subject/ client is made aware that they too should be the focus of the care and nurturing of others.

Much of the discussions of the personal problems brought up in the various exercises by the participants in the same NLP course were in line with what Bondi noticed in the case of the counsellors she analysed:

${ }^{4}$ All names appearing in the paper are fictional and details that are irrelevant for the purposes of the argument have been slightly modified in order to insure the anonymity of the subjects. 
Although these counsellors focus on the effects of counselling for individuals, they do not imagine these people in isolation from others. They do not necessarily assume that empowering individuals is about supporting them to prioritise their own needs over others, because they assume that most people's needs are fundamentally relational (Bondi 2005:507).

I recall two cases of women participants, above 45 years old, having grown-up children who were dissatisfied with the relationship they had with them. Andreea did not know how to do a better job in helping her daughter with her daily responsibilities and how to offer better guidance in relation to the job choices she was currently facing. Andreea was a mother worried that her daughter was making poor career-related choices and wanted to handle the situation better. What the trainer did with the idea of the responsibility of the individual is that she painted a world in which intentions are not the same as actions: the good intentions of the mother were recognized, as well as the importance of the tie with her daughter. However, the trainer asserted the limits of the responsibility of a person towards their children and the necessity to recognize their own lives and decisions, their own autonomy. What the trainer told Andreea was that is was not in her power to change the situation, as if it were completely in her hands, but she could change her attitude in such a way as to acknowledge the autonomy of the other person and to think of herself as an autonomous individual to whom attention, care, and interest should be directed at. This did not challenge the values of parenthood of the clients, rather drew some boundaries of responsibility. In regard to the patriarchal norms of the individuality-less mother, this is actually an empowering move, calling for mutuality, not for disconnectedness.

Given the socially pervasive script for motherhood that makes care for children and husband central, and assigns little importance to the mother's own emotional needs, or her space for individuality, the workshop actually worked towards establishing a sense of boundaries and of mutuality between children and mothers, as well as between husband and wife. This was not done in the spirit of families lacking the function of nurturing and help, but insisted on a more balanced division of emotional work. In no occasion were the participants invited to imagine themselves as disconnected from the others, and healthy, deep, and thriving relationships have consistently been presented as desirable.

\section{Community and changing the system}

One of the elements severely missing from most of the visions of change that the subjects in our research project discussed is that of the community. While many of the practices of spiritual and personal development happen in 
groups, the role of the group is transitory and does not have a purpose beyond the moment of the encounter. The interactions between participants in a workshop are most times viewed as crucial for each person's development. However, this importance is limited to the confined space of that interaction, and individuals are interchangeable: in any group of unknown people one would find the type of alterity needed to interact with in order to achieve the purpose of self-knowledge.

Out of the entire fieldwork experience within the research project, it was only in the discourse of one particular trainer that I have identified a significant difference on this dimension. Throughout the public presentation of her future working group and in her later on-line posts, she emphasized the importance of the community created around these meetings outside the context of the meetings themselves. Letiția, a 34 years old business graduate, with a significant experience of working in multinational companies and for a business consulting firm, was starting a spiritual development group, which explicitly valued both business success and spiritual development. The way she encouraged the participants in this first meeting to bring friends was not only a way to increase the number of participants, but was important in her vision about what her work consisted of. She thought of the participants not only in terms of interchangeable individuals who shared the purpose of selfbetterment and therefore benefit from each other's presence in the workshop, but because they potentially represented concrete resources for the other people in order to start projects together (either businesses or any type of policy).

There will be new people coming at each meeting. My intention is to create a community. A community that will most likely keep in touch most easily virtually, if at some point we'll end up being a very large group. You know, from different domains, with different businesses. This is what I do now - I go from place to place and I connect people amongst each other, so that they share ideas, they share resources. Because we want to change the system, but we don't know what to do... we don't have a shared vision. [...] it's so important to meet people personally, to make sure, before you start a project together that you share the same ideas, to know them, to develop in these meeting a shared understanding... some shared principles on how to be in the world, how to do things. The community is so important, you can't do things alone, you get tired. We must reach out to others who are the same as we are (Letiția, 34 years old, female, business background).

Another interesting mutation from the standard discourse was the way she referred to the "system". It was not only presented as a construct used by people to delegate responsibility, but an actual area on which intervention can be legitimately and even imperatively sought. The majority of the discourses I have encountered refer to identifying problems with 'the state', 'the government', 
'the country', 'politicians' as a misleading move, as a fallacy through which individuals deflect their own responsibility for their life situations. Both in interviews and in the live discussion in the workshops I refer to, such diagnosis were singled out and then a restatement of the importance of the individual level followed. For Letiția, however, actual change could be achieved only by combining careful crafting of the self with interventions at the systemic level. This is a very different emphasis that I have only briefly encountered in other interviews.

Any system - even the system that we have now - was generated by some people, who were confronted with realities being different than what they would have wanted, and they came with their genius, with their expertise, with what they knew, what they wanted, what they were good at and they wrote some papers that they then named The Declaration of Independence, or a law, or... All things were generated by people, by individuals. If we want something new today, it's still going to come from the people who are in the systems, those who are in the administration, they are the ones who know what is going on there, what needs to change. And maybe they need an impulse. Maybe the moment you are a tiny person, you're like a dot, you feel crushed, you have the feeling that no one can hear you, it's very difficult to change the system. But if you find someone similar, someone who thinks the same in all that system, it's that person that you need to meet. And do things (Letiția, 34 years old, female, business background).

Due to her personal experience in trainings with people working in the state sector, she discussed how actually these people were caught in the logic of the system, even if they might see things differently and want to act upon their vision. Therefore, in her view only by acting upon the system from within can actual change be achieved.

Letitia: [...] But not with the old mentality of "fine, fine, but what do I get out of this". I have a friend who...

Interruption from the public: This is exactly what I was thinking about - your project is a very brave one. I mean if you talk about the people from the state sector... how are they going to work with one another?! "What am I getting out of this" this is how they think. Because us, the rest, I think we're more open to volunteering, because we live in the real world. You see you can't just stay in muddy water, and that even if you do it for free, you need to contribute to cleaning it... simply because you can't stand yourself like this... But them... I'm not sure.

Letitia: I've worked with politicians. The consulting firm I worked with had to work with politicians, with local administration on some projects. And it is like this that I had the chance to get to the person, to the person behind the position. 
They are people too, they have their values, their desires, and they do the best they can in the system they are in. Don't think it's easy to change the system just because you want to! Many of them would want to, but... So whom they interact with matters, it can lead to change (Letiția, 34 years old, female, business background).

What is interesting is rather the fact that the system itself is the object of change, not only the self. What we have in this case is not the typical vision that one should only focus on bettering their own lives, as the benefits will trickle up (and down) from there to others as well ("many happy selves make for a happy universe"), but include the preoccupations for actively intervening in changing supra-individual entities in the realm of legitimate objects of change.

And the moment everyone is involved in a small betterment, $1 \%$ in each life, the moment there are a few hundreds of thousands, you'll see a change globally. In five years that's where you'll get [...] How do we change things, how do we stay confident in the fact that we can change something. As you were saying: "I go to a course, then I go back to my life and what happens?" Entropy! Resistance to change, any system has entropy, it does not want to change. Why? Because the brain works on the principle of energy saving. If my brain worked for ten years on some neurological paths and I went once and I lived a new experience for five days... what happens after that new experience is over? My brain prefers to take the walked path because it costs less. What needs to be done in order to encourage your brain to expose itself to new ways of doing things? Presence. Mindfulness. Mindfulness puts the brain in alert and keeps you on your path [...] And then you see results, in your life, in the life of others, in the system you're in (Letiția, 34 years old, female, business background).

However, the vision is that of incremental change stemming from changes in subjectivities, albeit with the orientation towards the supra-individual level. Nonetheless, this does not guarantee the direction in which the system is to be changed, but it does go against the conventional wisdom that these practices of subjectivation completely shut down the individual from the systems she takes part in.

\section{Final remarks}

The intention of my analysis was to document some of the mutations that can be identified in the actual practices of subjectivity production within a loosely defined field of personal and spiritual development. The material above can be questioned (like any religious/marketing practice) in terms of the authenticity of any move that takes distance from the economic pursuit of 
profit. For example, Letiția's emphasis on the importance of community can easily be read as a novel PR strategy for her business. Indeed, as the field of providers of services of personal and spiritual development becomes denser with time, it is often the case that consumers meet in more than one such workshop or course. Therefore, a rational strategy for a provider could be to make use of the networks that might form in this way, to try to incorporate them into their strategy, instead of attempting to reach out for untapped new publics. However, the ambivalences I refer to are not only relevant insofar as they would prove to be completely outside of the logic of the market for the producers. This complete separation would be inconceivable, as the very logic in which the subjects were selected for this research involved them being providers of services.

The importance of taking notice of these ambivalences comes from the openings they offer for the clients in relation to the world view they foster. The very power of such practices of subjectivation is said to emerge from the type of definition of themselves it invites individuals to adhere to, definitions of others, of the system, of the link between the individual and the system that they instil, the actions and the ways of being that it presents as desirable or acceptable and those that it paints as incorrect. The underlying assumption of the critical literature focusing on the formation of neoliberal subjectivity is that these types of representations constituting the scripts for subjectivity have a real effect in the ways individuals act and participate in society. The same should hold true for those elements that fail to align themselves to the neoliberal logic, and therefore ambivalences should not be thought of as inconsequential.

\section{REFERENCES}

Binkley, S. (2009). The Work of Neoliberal Governmentality: Temporality and Ethical Substance in the Tale of Two Dads. Foucault Studies (6):60.

Binkley, S. (2011). Happiness, positive psychology and the program of neoliberal governmentality. Subjectivity 4:371-394.

Bondi, L. (2005). Working the spaces of neoliberal subjectivity: Psychotherapeutic technologies, professionalisation and counselling. Antipode 37(3):497-514.

Chertkovskaya, E. (2013). Consuming work and managing employability: students' work orientations and the process of contemporary job search. Loughborough University, Business School, unpublished PhD Thesis.

Chertkovskaya, E.; Watt, P.; Tramer, S.; Spoelstra, S. (2013). Giving notice to employability. Ephemera: Theory and Politics in Organization 13(4):701-716. 
Dassinger, J. (2013). Managing the Unemployed No More: Renewing Union Adjustment Through Pedagogy of Resistance. Review of Education, Pedagogy, and Cultural Studies (March 2015): 37-41.

Fejes, A. (2010). Discourses on employability: Constituting the responsible citizen. Studies in Continuing Education 32(2):89-102.

George, M. (2013). Seeking legitimacy: The professionalization of life coaching. Sociological Inquiry 83(2):179-208.

Jaramillo, N.E.; Carreon, M.E. (2014). Pedagogies of resistance and solidarity : towards revolutionary and decolonial praxis. Interface: a journal for and about social movements 6(1):392-411.

Makinen, K. (2014). The individualization of class: A case of working life coaching. Sociological Review 62(4):821-842.

McQuaid, R.; Green, A.; Danson, M. (2005). Introducing employability. Urban Studies 42(2): 191-195.

Morgen, S.; Gonzales, L. (2008). The Neoliberal American Dream as Daydream: Counterhegemonic Perspectives on Welfare Restructuring in the United States. Critique of Anthropology 28(2): 219-236.

Pagis, M. (2016). Fashioning Futures: Life Coaching and the Self-Made Identity Paradox. Sociological Forum 31(4): 1083-1103.

Petrovici, N. (2015). Personal Development and the Flexible Contracts: Depoliticized Class Struggles between Highly Skilled Workers and Manual Workers in Cluj. Retrieved from http://www.erstestiftung.org/social-research/publication/personaldevelopment-and-the-flexible-contracts/

Simionca, A. (2015). The Precariousness of the Employable. Highly Skilled Professionals in Contemporary Romania. Retrieved from http://www.erstestiftung.org/socialresearch/publication/the-precariousness-of-the-employable/

Ten Bos, R.; Rhodes, C. (2003). The game of exemplarity: subjectivity, work and the impossible politics of purity. Scandinavian Journal of Management 19(4):403423.

Trifan, E. (2015). Coaching and personal development: the construction of the self in a community of practice in Bucharest. Romanian Journal of Society \& Politics: 119-132.

Türken, S.; Nafstad, H.E.; Blakar, R.M.; Roen, K. (2015). Making Sense of Neoliberal Subjectivity: A Discourse Analysis of Media Language on Self-development. Globalizations 7731(July):1-15.

Wilthagen, T. ; Tros, F. (2004). The concept of 'flexicurity': a new approach to regulating employment and labour markets. Transfer: European Review of Labour and Research 10(2):166-186. 